\title{
Effect of Fermentation on the Factor of Skin Pigmentation Inhibitory Activity and Total Antioxidant Capacities Demonstrated by the South African Rooibos (Aspalathus linearis)
}

\author{
Olugbenga Kayode Popoola ${ }^{1 *}$, Temidayo Oluwasegun Adedara ${ }^{2}$, Adeola Taoreed Ajao ${ }^{2}$, \\ Mayowa Akinrinlola ${ }^{1}$ and Akinyemi Oluwafemi Olasanmi ${ }^{1}$ \\ ${ }^{1}$ Department of Chemistry, Faculty of Science, Ekiti State University, Ado-Ekiti, Nigeria \\ ${ }^{2}$ Department of Industrial Chemistry, Faculty of Science, Ekiti State University, Ado-Ekiti, Nigeria \\ *Corresponding author: Olugbenga K. Popoola, Department of Chemistry, Faculty of Science, Ekiti State University, Ado-Ekiti, \\ Nigeria
}

\section{ARTICLE INFO}

Received: 慧 August 09, 2019

Published: 蔧 August 16, 2019

Citation: Olugbenga Kayode Popoola, Temidayo Oluwasegun Adedara, Adeola Taoreed Ajao, Mayowa Akinrinlola, Akinyemi Oluwafemi Olasanmi. Effect of Fermentation on the Factor of Skin Pigmentation Inhibitory Activity and Total Antioxidant Capacities Demonstrated by the South African Rooibos (Aspalathus linearis). Biomed J Sci \& Tech Res 20(4)-2019. BJSTR. MS.ID.003481.

Keywords: Aspalathus linearis, polyphenols, herbal tea, skin pigmentation, oxidative stress, fermentation

\begin{abstract}
Rooibos (Aspalathus linearis (Brum.f) Dahlg.), is an economic plant of South Africa known to be a rich source of phytochemicals, including its health beneficial polyphenols thereby ascribed a global recognition in the preparation of herbal tea. In this study, chloroform and ethanol extracts of both green and fermented rooibos were subjected to preliminary phytochemical and thin layer chromatography (TLC) using anti-tyrosinase bio-autographic screening. The most bioactive green rooibos ethanolic extract (GRE) was fractionated using a gradient of TLC-guided column chromatographic method. The constituents of the fractions obtained were identified by analytical highperformance liquid chromatography/ultra-violet detector (HPLC/UV). In vitro biological activities demonstrated by GRE/FRE (fermented rooibos ethanol extract) include: skin depigmentation (85.837 $\pm 1.722 / 58.703 \pm 4.184 \%$ at $1 \mathrm{mg} / \mathrm{mL}$ ); Iron (II)-induced lipid peroxidation inhibition ( $59.170 \pm 0.869 / 42.344 \pm 1.655$ at $1 \mathrm{mg} / \mathrm{mL})$; ORAC and TEAC $(38.653 \pm 0.761 / 10.317 \pm 2.722$ and $7.320 \pm 2.465 / 2.559 \pm 3.601) \mu \mathrm{M} \mathrm{TE} / \mathrm{g} X 103$ and FRAP $(6.187 \pm 0.014 / 1.156 \pm 0.220) \mu \mathrm{M}$ AEE/g X $10^{3}$ respectively. Most of the activities demonstrated by GRE were in competitive manner to that of the commercial skin depigmenting agent kojic acid with \% inhibition of $99.179 \pm 0.945 \%$ at $1 \mathrm{mg} / \mathrm{mL}$ and that of antioxidant EGCG with $83.062 \pm 0.309 \%$ at same concentration. The results obtained propose the unfermented rooibos to have good antioxidant and tyrosinase inhibitory activity as an indication of having diverse health promoting properties, especially to alleviate the occurrence of diseases associated with oxidative stress thereby promoting its universal acceptability as both economic and medicinal plant.
\end{abstract}

\section{Introduction}

Oxygen has positive benefits and potentially damaging properties in biological systems. It is a highly reactive molecule, which participates in a high-energy electron transfer and through oxidative phosphorylation thereby supports generation of adenosine-5-triphosphate (ATP) [1]. This makes reactive oxygen species (ROS) liable to attack any biological molecule including cellular components such as lipids, deoxyribose nucleic acid (DNA) and proteins by accepting their electrons [2]. Such interactions may result in cellular damage such as lipid peroxidation, protein fragmentation, charge alteration, conformational changes, alteration of gene expression [3], and most importantly, premature skin aging such as formation of pigment on the surface of the skin [4], leading to biological implications of diseases associated with oxidative stress [5].

Aspalathus linearis (Brum.f Dahlg.) globally known as rooibos is a fynbos species, which grows naturally in the Cederberg Mountains, western parts of the Western Cape Province, South Africa. The rooibos plant has made the transition from being a wild resource to become a plant of great agricultural and economic importance [6] with total production including unfermented rooibos was in excess 
of 14,000 tons [7]. It is people's belief that rooibos tea possesses antispasmodic properties, as well as to relieve digestive troubles among others $[8,9]$.

After harvesting, the plant material can be subjected to a fermentation process where it is bruised and oxidized in open air. The processed tea is referred to as fermented rooibos, while the unprocessed tea is referred to as "green" or unfermented rooibos [10]. In both green and fermented rooibos, phenolic compounds are present, but the concentration of polyphenols and flavonoids decrease during the fermentation process. An analysis of both plants has showed a higher total polyphenol content in green (41.2 $\%$ ) than in fermented rooibos (29.7\%). The decrease of polyphenols in fermented rooibos was mostly caused by loss of flavonoids [11]. The differences are ascribed to the enzymatic and chemical changes during fermentation, and the drying method used [12]. Rooibos have a unique flavonoid composition, containing rare compounds as previously described [13-16], with varying degree of biological potentials including antimutagenic [17], highly active free radical scavenger [18], lowering of oxidative stress through scavenging of ROS, reducing free radical generation, anti-inflammatory and anticarcinogenic effects [19], and anti-lipid peroxidative potential [20]. Health beneficial effect of daily consumption of both fermented and green rooibos were also established and found to possess good antioxidant capacity by improved lipid profile as well as redox status, thereby averting ailments associated with cellular oxidative stress [21]. Scientific database has documented numerous phytochemical, biological and health beneficial effect of rooibos. Nevertheless, skin depigmentation property this plant has not been investigated. This study is therefore important to establish a background information on possibility of alleviating the formation of pigments on the surface of the skin using either green or its fermented plant. Other skin aging related biological implications were also assessed on the two plant materials in an in vitro system.

\section{Materials and Methods}

\section{Chemicals and reagent}

Kojic acid, epigallocatechin gallate (EGCG), 6-hydroxy-2,5,7,8tetra-methylchroman-2-carboxylic acid (Trolox), 2,2'-azinobis(3-ethylbenzothiazoline-6-sulfonic acid) diammonium salt (ABTS), potassium peroxodisulphate, fluorescein sodium salt, 2,2'-azobis(2-mehtyl-propionamidine) dihydrochloride (AAPH), 2,4,6-tri[2-pyridyl]-s-triazine (TPTZ), iron (III) chloride hexahydrate, monosodium phosphate, disodium phosphate and skin enzyme tyrosinase (from mushroom) were purchased from Sigma-Aldrich, Inc. (St. Louis, MO, USA). Methanol, ethanol, ethyl acetate, dimethyl sulfoxide (DMSO), chloroform, vanillin sulphuric acid, L-tyrosine, trifluoroacetic acid (TFAA), sodium acetate, glacial acetic acid, hydrochloric acid (HCl), L-ascorbic acid, trichloroacetic acid (TCA), ethylenediaminetetraacetic acid (EDTA), butylated hydroxytoluene (BHT), iron (II) sulfate $\left(\mathrm{FeSO}_{4}\right)$, potassium chloride $(\mathrm{KCl})$, potassium phosphate $\left(\mathrm{KH}_{2} \mathrm{PO}_{4}\right)$, gallic acid, tert-butyl alcohol
(TBA), acetonitrile and hexane were purchased from Pascal scientific Ltd (Akure, Nigeria).

\section{Preparation of plant extracts}

Green and fermented rooibos plant material from Clan William in the Cederberg region $\left(32^{\circ} 30^{\prime} \mathrm{S} 19^{\circ} 0^{\prime} \mathrm{E}\right)$, Western Cape, South Africa, was supplied by Rooibos Ltd. Both samples, $200 \mathrm{~g}$ each, were extracted with chloroform $(20 \% \mathrm{~m} / \mathrm{v}$ ) for 24 hours at room temperature $\left(25^{\circ} \mathrm{C}\right)$, then filtered through filter paper (Whatman No. 2) to remove chlorophyll and lipophilic constituents. The plant materials (residue) were further extracted with absolute ethanol $(20 \% \mathrm{~m} / \mathrm{v})$ for 24 hours at room temperature $\left(25^{\circ} \mathrm{C}\right)$ and filtered. The chloroform and ethanol filtrates of both samples were evaporated to dryness under reduced pressure using a rotary evaporator (BÜCHI Rotavapor R-114) at $35^{\circ} \mathrm{C}$, to produce two different extracts of chloroform and ethanol, and stored at $4{ }^{\circ} \mathrm{C}$.

\section{Preliminary phytochemical screening of plant extracts}

$1 \mathrm{mg}$ of the dried ethanol and chloroform extracts from both fermented (FRC \& FRE) and green (GRC \& GRE) rooibos were dissolved in $1 \mathrm{~mL}$ ethyl acetate $(1 \mathrm{mg} / \mathrm{mL}$ ) for TLC-profiling. The samples $\left(50 \mu \mathrm{L}\right.$ each) were spotted on commercial silica $\mathrm{PF}_{254}$ plate $(7 \times 6 \mathrm{~cm})$ coated on aluminum foil as stationary phase with spotting capillary tube. A $5 \mathrm{~mL}$ solution of hexane and ethyl acetate $(9: 1, v / v)$ was used as the mobile phase in a chromatographic tank. The development of the plate was done followed by identification of the class of organic constituents in the extracts under UV lamp (254 and $366 \mathrm{~nm}$ ) and then vanillin sulphuric acid spray reagent.

\section{Preliminary anti-tyrosinase TLC bio-autography screening of plant extracts}

The TLC bioautographic assay of tyrosinase inhibition was performed as described previously with slight modifications [22]. Phosphate buffer (PBS) was prepared by mixing two stock solutions of monosodium phosphate $50 \mathrm{mM}$ and disodium phosphate $50 \mathrm{mM}$ to the $\mathrm{pH}$ 6.5. Tyrosinase solution was prepared by dissolving $1 \mathrm{~mL}$ of $1000 \mathrm{U}$ enzyme in $1 \mathrm{~mL}$ of phosphate buffer. The substrate was prepared by dissolving $0.0036 \mathrm{~g}$ of L-tyrosine in $10 \mathrm{~mL}$ phosphate buffer. Extracts and kojic acid were dissolved in methanol to a stock solution of $1 \mathrm{mg} / \mathrm{mL}$. After spotting $15 \mu \mathrm{L}$ of the extracts and kojic acid (positive control) onto the TLC plate, the plate was developed using solvent system hexane:ethyl acetate $(7: 3 \mathrm{v} / \mathrm{v})$. The developed plate was then sprayed with tyrosinase and incubated at room temperature for $5 \mathrm{~min}$, followed by L-tyrosine $(20 \mathrm{mM})$ and left at room temperature for $30 \mathrm{~min}$. The background of the plate assumed a purplish-grey colour and clear white zones of tyrosinase inhibition were observed, indicating the presence of bioactive constituents in the samples.

\section{TLC-guided column chromatographic fractionation}

The most bioactive extract (GRE) was subjected to TLC- guided column chromatography. The fermented rooibos ethanol extract (GRE, $5.5 \mathrm{~g}$ ) was dissolved in ethyl acetate and pre-adsorbed onto 
silica in a petri dish for 5 hours. The column $(24 \times 14 \mathrm{~cm})$ was packed with silica and added to the top of the stationary phase. The flow rate $(8.5 \mathrm{~mL} / \mathrm{min})$ of the mobile phase solvent system was a gradient of hexane, ethyl acetate and methanol. The collected fractions (GRE 1-19) were concentrated under reduced pressure (rotavapor) and developed on TLC with solvent systems (Hexane:ethyl acetate $9: 1 ; 7: 3 ; 1: 1)$. Fractions of the same TLC characteristics under UV $(254 ; 366 \mathrm{~nm})$ and when sprayed with vanillin sulphuric acid were combined to yield 9 main fractions coded GRE I-IX.

\section{Determination of constituents of GRE using HPLC/UV}

Determination of polyphenolic compounds from combined fractions labelled I-IX was carried out on a reverse-phase analytical HPLC. This was done using Agilent 1200 series, equipped with UVdetector, automatic injector, quaternary pump, vacuum degasser and column compartment. The UV-detector was set at $287 \mathrm{~nm}$ for detection of aspalathin and $360 \mathrm{~nm}$ for detection of all other compounds, with a bandwidth of $4 \mathrm{~nm}$. The mobile phases were made up of water and acetonitrile containing a diluted $(0.03 \%)$ trifluoroacetic acid (TFAA). The elution process was carried out using various time dependent compositions of the mobile phases as acetonitrile/water: $35 / 65$ at $5 \mathrm{~min} ; 80 / 20$ at $25 \mathrm{~min}$; 35/65 at $28 \mathrm{~min} ; 35 / 65$ at $30 \mathrm{~min}$. The entire experiment was carried out at $23{ }^{\circ} \mathrm{C}$ with silica column C-18-micron, internal diameter: $150 \times 4.60$ $\mathrm{mm}$. The flow rate was set at $1 \mathrm{~mL} / \mathrm{min}$ and the injection volume was $2 \mu \mathrm{L}$.

\section{Ferric-Reducing Antioxidant Power (FRAP) assay}

FRAP was measured according to the method described [23]. FRAP reagent was prepared by mixing $30 \mathrm{~mL}$ acetate buffer, $3 \mathrm{~mL}$ TPTZ solution, $3 \mathrm{~mL} \mathrm{FeCl}_{3}$ solution, and $6.6 \mathrm{~mL}$ distilled water in a $50 \mathrm{~mL}$ screw cap tube. $10 \mu \mathrm{L}$ of the samples, ascorbic acid standards, and EGCG control was added in triplicates in designated wells in a clear well plate. $300 \mu \mathrm{L}$ of the FRAP reagent was added to each well using a multichannel pipette. The plate incubated in the dark at room temperature for 30 minutes before reading. The samples were measured at $593 \mathrm{~nm}$.

\section{Trolox-Equivalent Antioxidant Capacity (TEAC) assay}

TEAC was measured according to the method described [23]. The ABTS mix was diluted with ethanol to read an absorbance of $2( \pm 0.1)$ in the plate reader. $25 \mu \mathrm{L}$ of the trolox standards, the samples and the EGCG as positive control were added in triplicates to designated wells in a clear well plate. $275 \mu \mathrm{L}$ of the ABTS mix was added to each well using a multichannel pipette. The plate incubated in the dark at room temperature for 30 minutes before reading. The samples were measured at $734 \mathrm{~nm}$.

\section{Oxygen Radical Absorbance Capacity (ORAC) assay}

ORAC was measured according to the method described [24]. Trolox standard series were diluted in PBS (75 mM, pH 7.4) which was previously prepared by mixing $18 \mathrm{~mL}$ of $75 \mathrm{mM}$ sodium phosphate with $82 \mathrm{~mL}$ of $75 \mathrm{mM}$ disodium phosphate. 12 $\mu \mathrm{L}$ of trolox standards and samples were added in triplicates to designated wells in a black 96-well plate. Fluorescein stock solution was previously prepared by dissolving $0.0225 \mathrm{~g}$ fluorescein sodium salt $\left(\mathrm{C}_{20} \mathrm{H}_{10} \mathrm{Na}_{2} \mathrm{O}_{5}\right)$ in $50 \mathrm{~mL}$ PBS. This solution was diluted by adding $10 \mu \mathrm{L}$ fluorescein stock solution to $2 \mathrm{~mL}$ phosphate buffer, and then further diluted $240 \mu \mathrm{L}$ of the new solution in $15 \mathrm{~mL}$ PBS. $138 \mu \mathrm{L}$ of fluorescein stock solution diluted in PBS was added to each of the wells. $50 \mu \mathrm{L}$ of peroxyl radical AAPH dissolved in PBS to a concentration of $25 \mathrm{mg} / \mathrm{mL}$, was added to each well. The decay in fluorescence was measured with a fluorescence detector at $486 \mathrm{~nm}$ excitation and $538 \mathrm{~nm}$ emission wavelengths. The ORAC value was calculated by dividing the sample curve-area by the trolox curvearea.

\section{Fe (II)-Induced microsomal lipid peroxidation (LPO) assay}

LPO was measured according to the method described (Snijman et al. 2009) with some modifications [4]. TCA -EDTA solution was prepared by dissolving $10 \mathrm{~g}$ of TCA and $29.2 \mathrm{mg}$ of EDTA in $100 \mathrm{~mL}$ distilled water, then a BHT solution was made by dissolving $0.8 \mathrm{~g}$ BHT in $10 \mathrm{~mL}$ ethanol. TCA reagent $(10 \%$ TCA, BHT \& 1 mM EDTA) was then made by adding $0,125 \mathrm{~mL}$ of the BHT solution to $100 \mathrm{~mL}$ TCA-EDTA solution. TBA $(0.67 \%)$ solution was prepared by dissolving $0.67 \mathrm{~g}$ of TBA in $100 \mathrm{~mL}$ distilled water. $\mathrm{FeSO}_{4}$ solution was prepared by dissolving $139 \mathrm{mg}$ of $\mathrm{FeSO}_{4} \cdot 7 \mathrm{H}_{2} 0$ in $200 \mathrm{~mL}$ distilled water, to a $2.5 \mathrm{mM}$ solution. $\mathrm{KCl}$-buffer with 1.15 $\% \mathrm{KCl}$ containing $0.01 \mathrm{M}$ potassium phosphate buffer ( $\mathrm{pH} 7.4$ ) was previously made by dissolving $1.15 \mathrm{~g} \mathrm{KCl}$ and $1.7418 \mathrm{~g} \mathrm{~K}_{2} \mathrm{HPO}_{4}$ and $1.3699 \mathrm{~g} \mathrm{KH}_{2} \mathrm{PO}_{4}$ in $100 \mathrm{~mL}$ distilled water. Microsome blank was prepared by mixing $0.5 \mathrm{~mL} \mathrm{KCl-buffer}$ and $0.5 \mathrm{~mL}$ microsomes to a total volume of $1 \mathrm{~mL}$. EGCG was used as positive control. The samples and positive controls was prepared by incubating a mix of $50 \mu \mathrm{L}$ anti-oxidative solution corresponding to either the plant extracts or the positive controls and $300 \mu \mathrm{L}$ microsomes at $37{ }^{\circ} \mathrm{C}$ for $30 \mathrm{~min}$ in a shaking water bath, before $100 \mu \mathrm{L}$ of $\mathrm{FeSO}_{4}$-solution and $\mathrm{KCl}$-buffer was added. The samples were then incubated at $37^{\circ} \mathrm{C}$ for 1 hour in a shaking water bath. After the incubation 1 $\mathrm{mL}$ TCA reagent was added to each tube and further vortexed and centrifuged at $2000 \mathrm{rpm}$ for $15 \mathrm{~min}$. After the centrifugation $1 \mathrm{~mL}$ of the supernatant was removed and added to new test tubes in which $1 \mathrm{~mL} 0.67 \%$ TBA solution was added. The samples were further vortexed and heated for $20 \mathrm{~min}$ at $90^{\circ} \mathrm{C}$ in a water-bath. The microsomes, positive controls, and samples were then added in triplicates in designated wells in a clear well plate. The samples were measured at $532 \mathrm{~nm}$.

$\%$ inhibition $=\left[\left(\mathbf{A}_{\text {control }}-\mathbf{A}_{\text {sample }}\right) / \mathbf{A}_{\text {control }}\right] \times 100$

\section{Tyrosinase enzyme assay}

This assay was performed using a spectrophotometric method previously described [26]. PBS (50 mM) was prepared to $\mathrm{pH} 6.5$. Reagent blank (negative control) contained sodium phosphate buffer and enzyme without any inhibitor. Kojic acid was used as positive control. In the wells of a 96-well plate, $70 \mu \mathrm{L}$ of each sample working solution was combined with $30 \mathrm{~L}$ of tyrosinase 
(200 Units/mL in sodium phosphate buffer) in triplicate. Parallel to these wells' samples were added in triplicate with buffer instead of enzyme as sample control. After incubation at room temperature for $5 \mathrm{~min}, 110 \mathrm{~L}$ of substrate ( $2 \mathrm{mM} \mathrm{L}$-Tyrosine) was added to each well. $2 \mathrm{mM}$ L-tyrosine was prepared by mixing $0.036 \mathrm{~g} \mathrm{~L}$-tyrosine in $100 \mathrm{~mL}$ distilled water. Incubation commenced for $30 \mathrm{~min}$ at room temperature and the enzyme activity was determined by measuring the absorbance at $490 \mathrm{~nm}$. The percentage of tyrosinase inhibition was calculated as follows:

Tyrosinase inhibition $(\%)=[(A-B)-(C-D)] /(A-B) \times 100$
$A=$ Absorbance of control with enzyme;

$\mathrm{B}=\mathrm{Absorb}$ ance of the control without enzyme

$\mathrm{C}=$ Absorbance of sample with enzyme;

$\mathrm{D}=$ Absorbance of sample without enzyme

\section{Results and Discussion}

\section{Plant extraction}

The results of extraction of the plant materials (rooibos: green and fermented) using two different organic solvents: chloroform and then ethanol are depicted in Table1.

Table 1: Extraction and \% yield of plant material.

\begin{tabular}{|c|c|c|c|c|}
\hline Plant material & CODE & Solvent & Weight of Extract (g) & \% Yield \\
\hline \multirow{2}{*}{ Green Rooibos: $200 \mathrm{~g}$} & GRC & Chloroform & 1.361 & 0.68 \\
\cline { 2 - 5 } & GRE & Ethanol & 6.575 & 3.29 \\
\hline \multirow{2}{*}{ Fermented Rooibos: $200 \mathrm{~g}$} & FRC & Chloroform & 1.327 & 0.66 \\
\cline { 2 - 5 } & FRE & Ethanol & 5.843 & 2.92 \\
\hline
\end{tabular}

GRC: chloroform extract of green rooibos; GRE: ethanol extract of green rooibos;FRC: chloroform extract of fermented rooibos ; FRE: ethanol extract of fermented rooibos

The ethanol extract of both green (GRE) and (GRC) were found to possess higher \% yields (3.29 and 0.68 respectively) than their corresponding fermented extracts (FRE and FRC). This can be ascribed to loss in the concentration of polyphenols and flavonoids during the fermentation process [11]. The ethanol extracts of both green and fermented were found to lower than their chloroform counterparts possibly due to the polar nature of ethanol with polarity almost similar to that of water, a universal solvent widely employed traditionally and in rooibos herbal tea preparation.

\section{Preliminary phytochemical and anti-tyrosinase TLC bio-autographic screening}

The results of the preliminary phytochemical screening of the total extracts using solvent system (hexane:ethyl acetate 9:1 v/v) followed by vanillin sulphuric acid spray for identification of the class of organic compounds and finally investigated the tyrosinase bioautographic profile. The plates were visualized under UV lamp at wavelengths $254 \mathrm{~nm}$ and $366 \mathrm{~nm}$. The presence of visual bands

Table 2: Extraction and \% yield of plant material. at $254 \mathrm{~nm}$ represents conjugated compounds most especially polyphenols. GRE showed diverse class of organic compounds after sprayed with vanillin sulphuric acid, compared to other extracts (FRE, GRC \& FRC). GRE and the positive control (kojic acid; KA) also proved to have significant inhibitory effect on the tyrosinase enzyme when compared to other extracts. The background of the plate assumed a purplish-grey colour and clear white zones of tyrosinase inhibition were observed, indicating the presence of bioactive constituents with anti-tyrosinase activity in the samples. The number of bands (constituents) present in GRE coupled with anti-tyrosinase bio-autographic profile nominated this extract (GRE) as the most bioactive and therefore selected for further chemical and biological activities. The quantitative analysis for the total antioxidant revealed GRE with potent ORAC $(38.653 \pm 0.761 \mu \mathrm{M}$ TE/g x $10^{3}$ ); FRAP $6.187 \pm 0.014 \mu \mathrm{M} \mathrm{AAE} / \mathrm{g} \times 10^{3}$ ) and TEAC 7.320 $\pm 2.465 \mu \mathrm{M}$ TE$/ \mathrm{g} \times 10^{3}$ ). Other biological activities demonstrated by other fractions are reported in Table 2.Total Antioxidant capacities and Skin depigmentation Activities of Extracts.

\begin{tabular}{|c|c|c|c|c|c|}
\hline Extract & $\begin{array}{l}\text { ORAC (peroxyl) } \\
\left(\mu M \text { TE } / g \times 10^{3}\right)\end{array}$ & $\begin{array}{c}\text { FRAP } \\
\mu \mathrm{M} \text { AAE } / \mathrm{g} \times 10^{3}\end{array}$ & $\begin{array}{c}\text { TEAC } \\
\mu \mathrm{M} \text { TE } / \mathrm{g} \times 10^{3}\end{array}$ & $\begin{array}{c}\text { LPO } \\
\% \text { inhibition }\end{array}$ & $\begin{array}{c}\text { TYR } \\
\% \text { inhibition }\end{array}$ \\
\hline GRE & $38.653 \pm 0.761$ & $6.187 \pm 0.014$ & $7.320 \pm 2.465$ & $59.170 \pm 0.869$ & $85.837 \pm 1.722$ \\
\hline FRE & $10.317 \pm 2.722$ & $1.156 \pm 0.220$ & $2.559 \pm 3.601$ & $42.344 \pm 1.655$ & $58.703 \pm 4.184$ \\
\hline GRC & $5.059 \pm 11.437$ & $0.288 \pm 31.197$ & $0.408 \pm 2.013$ & $25.799 \pm 2.988$ & $33.240 \pm 5.913$ \\
\hline FRC & $4.238 \pm 24.194$ & $0.168 \pm 6.193$ & $0.385 \pm 2.363$ & $21.817 \pm 5.578$ & $17.816 \pm 2.776$ \\
\hline EGCG & $6.428 \pm 20.478$ & $1.665 \pm 0.167$ & $1.907 \pm 8.569$ & $83.062 \pm 0.309$ & - \\
\hline Kojic acid & - & - & - & $83.062 \pm 0.309$ & $99.179 \pm 0.945$ \\
\hline
\end{tabular}




\section{TLC-guided chromatographic fractionation of GRE}

The main fractions GRE (1-19), were combined according to their TLC characteristics to yield nine (9) combined fractions coded by roman numbers GRE (I-IX) and the chromatograms are presented in Figures 1-3. The combined fractions were developed on TLC (solvent systems hexane:ethyl acetate 9:1; 7:3; and 1:1), viewed under UV at $254 \mathrm{~nm}$ (Figure 1), $366 \mathrm{~nm}$ (Figure 2), then sprayed with vanillin sulphuric acid (Figure 3).

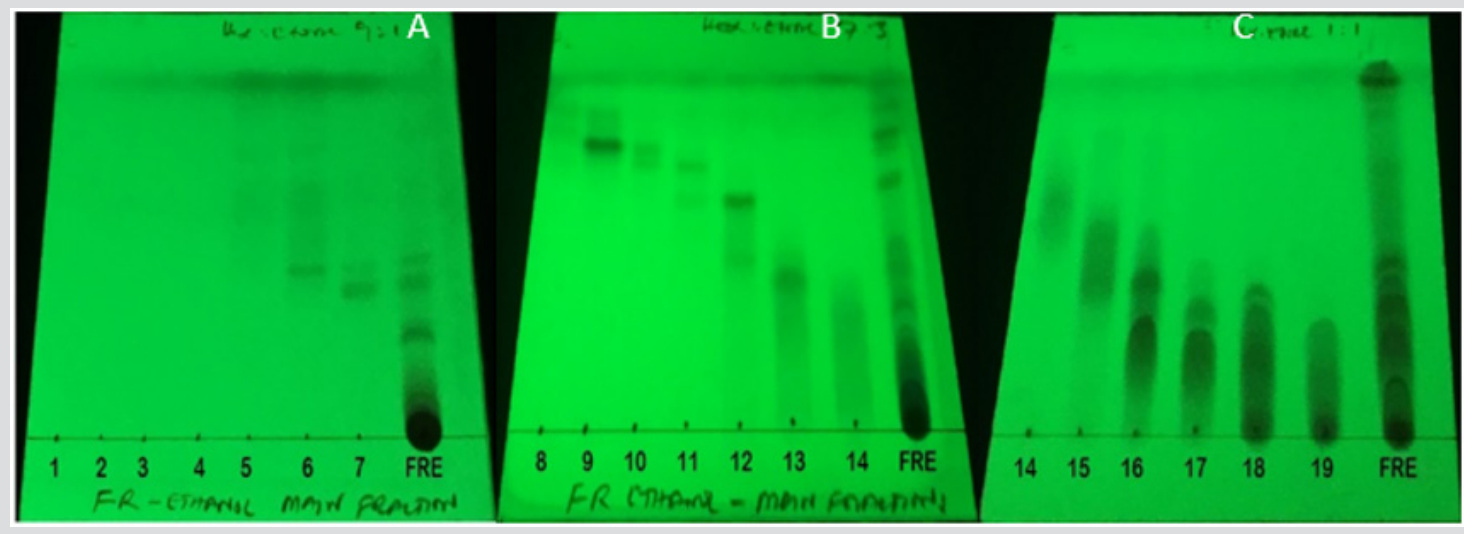

Figure 1: Phytochemical screening of collected fractions 1-19 and the total extract on TLC-plates (A), (B) and (C), with solvent system (Hex:EtAc, 9:1) for (A), and (Hex:EtAc, 3:7) for (B) and (Hex:EtAc, 1:1) for (C). Plates (A), (B) and (C) is displayed at 254 nm UV-light.

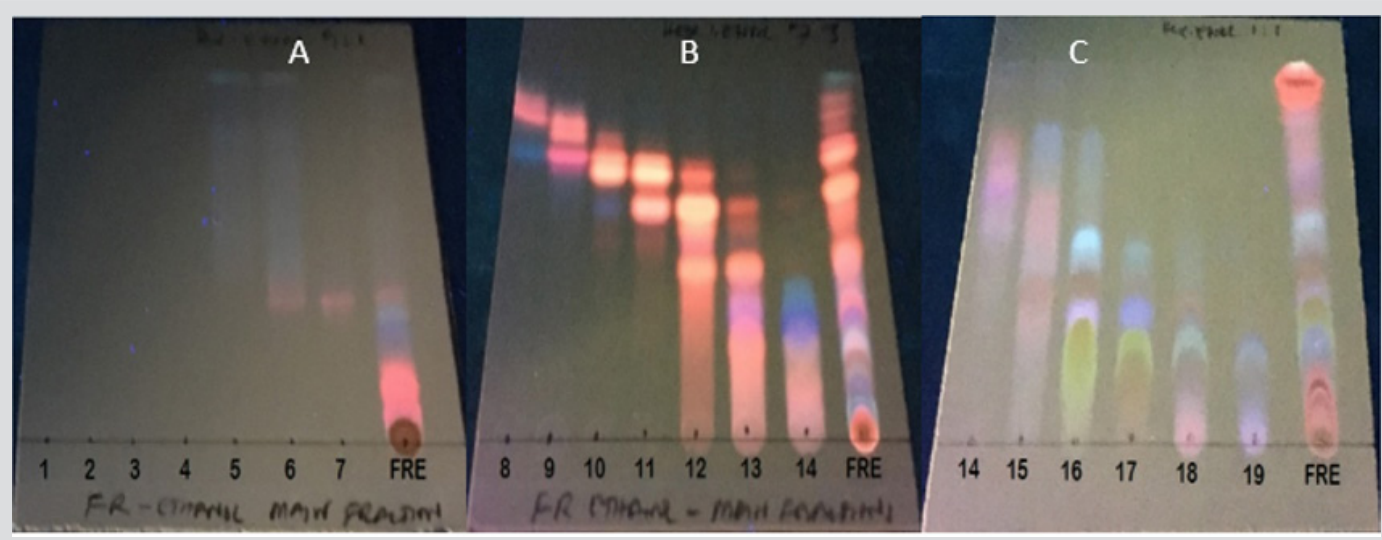

Figure 2: Phytochemical screening of collected fractions 1-19 and the total extract on TLC-plates (A), (B) and (C), with solvent system (Hex:EtOAc, 9:1) for (A), and (Hex:EtAc, 3:7) for (B) and (Hex:EtOAc, 1:1) for (C). Plates (A), (B) and (C) were viewed under UV lamp at $366 \mathrm{~nm}$ UV-light.

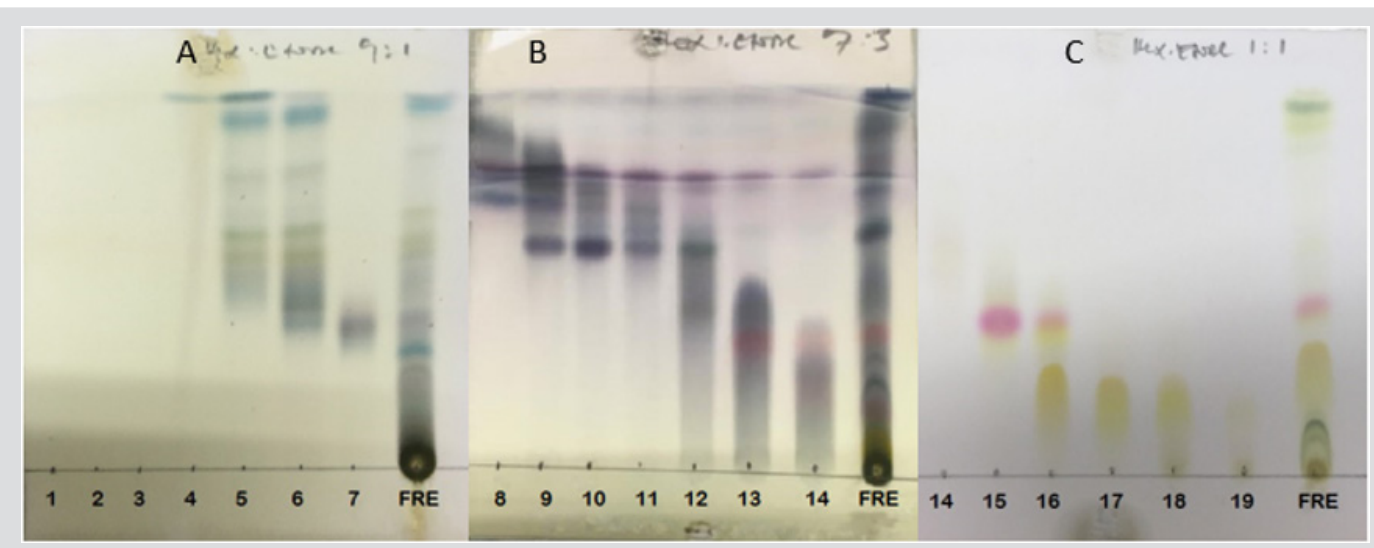

Figure 3: Phytochemical screening of collected fractions 1-19 and the total extract on TLC-plates (A), (B) and (C), with solvent systems (Hex:EtOAc, 9:1) for (A), and (Hex:EtOAc, 3:7) for (B) and (Hex:EtOAc, 1:1) for (C).The plate were sprayed with vanillin sulphuric acid.

\section{HPLC Identification of compounds}

Compounds identified from the HPLC spectral of GRE as well as their respective total antioxidant capacities are indicated in Table
3. Fractions VII, VIII and XI demonstrated the most active in peroxyl ORAC, FRAP and TEAC assays. The importance of quercetin and luteolin as potential antioxidants cannot be left out in the outcome 
of the results presented in Table 3 [27]. Our results aligned with previous data indicating FRE (VIII-IX) where compounds quercetin, luteolin and chrysoeriol were found to be the most prominent peaks. Such compounds are therefore likely to be responsible for the total antioxidant activities observed in the assays. This further indicates the importance of quercetin, luteolin and chrysoeriol in combating the pathological effects caused by free radicals, as are known to play an important role in free radical neutralization [27].

Table 3: Total antioxidant activities of the column chromatographic fractions.

\begin{tabular}{|c|c|c|c|c|}
\hline Fraction & Compound identified & $\begin{array}{c}\text { ORAC } \\
\mathrm{ROO} \cdot\left(\mu \mathrm{M} \mathrm{TE} / \mathrm{g} \times 10^{3}\right)\end{array}$ & $\begin{array}{c}\text { FRAP } \\
\mu \mathrm{M} \text { AAE } / \mathrm{g} \times 10^{3}\end{array}$ & $\begin{array}{c}\text { TEAC } \\
\mu \mathrm{M} \mathrm{TE} / \mathrm{g} \times 10^{3}\end{array}$ \\
\hline GRE & $\begin{array}{l}\text { Aspalathin (6.6), isovitexin (9.0), vitexin } \\
\text { (10.6), hyperoside/rutin (12.1), quercetin } \\
\text { (17.3), luteolin (18.3), chrysoeriol (20.5) }\end{array}$ & $38.653 \pm 0.761$ & $6.187 \pm 0.014$ & $7.320 \pm 2.465$ \\
\hline I & $\begin{array}{l}\text { Hyperoside/rutin (12.1), quercetin (17.2), } \\
\text { luteolin (18.3), chrysoeriol (20.2) }\end{array}$ & $0.764 \pm 12.336$ & $1.049 \pm 0.385$ & ND \\
\hline II & $\begin{array}{l}\text { Hyperoside/rutin (12.2), quercetin (17.2), } \\
\text { luteolin (18.3), chrysoeriol (20.1) }\end{array}$ & $1.200 \pm 9.036$ & $1.331 \pm 11.147$ & $0.428 \pm 9.514$ \\
\hline III & ND & $7.858 \pm 9.062$ & $1.149 \pm 14.463$ & $1.009 \pm 16.878$ \\
\hline IV & $\begin{array}{c}\text { Vitexin (10.5), quercetin (17.0), luteolin } \\
\text { (19.9), chrysoeriol (20.2) }\end{array}$ & $9.238 \pm 6.525$ & $1.163 \pm 1.932$ & $1.935 \pm 22.318$ \\
\hline V & $\begin{array}{l}\text { Orientin (6.9), vitexin (10.5), quercetin } \\
(17.0) \text {, luteolin (18.5), chrysoeriol (20.2) }\end{array}$ & $5.475 \pm 15.354$ & $1.093 \pm 3.301$ & $0.504 \pm 4.999$ \\
\hline VI & $\begin{array}{c}\text { Vitexin (10.6), hyperoside/rutin (11.7), } \\
\text { quercetin (17.0), luteolin (18.1), } \\
\text { chrysoeriol (20.2) }\end{array}$ & $5.393 \pm 11.720$ & $0.838 \pm 6.651$ & $0.424 \pm 9.020$ \\
\hline VII & $\begin{array}{c}\text { Orientin (6.7), vitexin (10.6), hyperoside/ } \\
\text { rutin (11.8), quercetin (17.2), luteolin } \\
\text { (18.2), chrysoeriol (20.3) }\end{array}$ & $46.806 \pm 15.561$ & $2.874 \pm 0.078$ & $4.701 \pm 2.349$ \\
\hline VIII & $\begin{array}{c}\text { Aspalathin (6.6), quercetin (17.1), luteolin } \\
\text { (18.3), chrysoeriol (20.4) }\end{array}$ & $62.618 \pm 12.408$ & $8.263 \pm 0.027$ & $4.071 \pm 76.685$ \\
\hline IX & $\begin{array}{c}\text { Vitexin (10.3), quercetin (17.7), luteolin } \\
\text { (18.3), chrysoeriol (20.3) }\end{array}$ & $75.842 \pm 4.815$ & $12.342 \pm 0.045$ & $20.909 \pm 1.710$ \\
\hline EGCG & - & $6.428 \pm 20.478$ & $1.665 \pm 0.167$ & $1.907 \pm 8.569$ \\
\hline
\end{tabular}

Figures in the bracket represent retention time measured in minute; ND: not detected

\section{Skin pigmentation inhibitory activity and LPO inhibition}

The tyrosinase enzyme assay reveals that GRE shows efficient tyrosinase inhibition with $85.837 \pm 1.722 \%$ at $1 \mathrm{mg} / \mathrm{mL}$ while that of FRE could not be detected. Nevertheless, the collected fractions from this extract shows potent inhibitory effect. Fraction VI, VII and IX shows the potent tyrosinase inhibition of $86.823 \pm 3.645$; $71.552 \pm 0.776$ and $66.544 \pm 11.732 \%$ inhibition respectively at $1 \mathrm{mg} / \mathrm{mL}$ (Table 4) while kojic acid shows near full inhibition at same concentration. The LPO result indicated FRE had most inhibitory effect on lipid peroxidation (59.170\%) of all total extracts Fractions (Table 2), while fractions VIII and IX had most inhibitory effect on lipid peroxidation with $65.059 \pm \mathbf{0 . 5 3 8}$ and $61.582 \pm 0.879$ in \% inhibition respectively at $1 \mathrm{mg} / \mathrm{mL}$ (Table 4 ). This is an indication that these fractions contain quercetin, luteolin and chrysoeriol with abilities to inhibit degradation of lipids due to oxidative damage. Consequently, antioxidants are essential in quenching ROS responsible for oxidative stress in tissue [3,28,29]. Quercetin, luteolin and chrysoeriol were the major components identified from the column fractions GRE (I-IX). The biological activities demonstrated by fractions VII-IX may be attributed to the presence of quercetin, luteolin and chrysoeriol, while the antityrosinase activity of fraction VI may be attributed to vitexin and rutin as well as quercetin and luteolin [30]. Rutin is also known to possess tyrosinase inhibitory effect due to its phenolic groups and exerts its inhibitory effect through copper-chelation [31]. The antityrosinase activity demonstrated by fraction VI (86.823 \%) may be linked with previous activities demonstrated and documented by the identified compounds [32-34].

Table 4: Skin depigmentation and anti-lipid peroxidation activities of the column chromatographic fractions.

\begin{tabular}{|c|c|c|c|}
\hline Fraction & Compound identified & $\begin{array}{c}\text { Lipid peroxidation } \\
\text { (\% inhibition) }\end{array}$ & $\begin{array}{c}\text { Tyrosinase } \\
\text { (\% inhibition) }\end{array}$ \\
\hline GRE & $\begin{array}{c}\text { Aspalathin (6.6), isovitexin (9.0), vitexin (10.6), hyperoside/rutin } \\
\text { (12.1), quercetin (17.3), luteolin (18.3), chrysoeriol (20.5) }\end{array}$ & $59.170 \pm 0.869$ & $85.837 \pm 1.722$ \\
\hline I & Hyperoside/rutin (12.1), quercetin (17.2), luteolin (18.3), \\
chrysoeriol (20.2) & $2.075 \pm 40.530$ & $59.031 \pm 11.301$ \\
\hline II & Hyperoside/rutin (12.2), quercetin (17.2), luteolin (18.3), \\
chrysoeriol (20.1) & $48.233 \pm 1.41$ & $26.806 \pm 2.776$ \\
\hline
\end{tabular}




\begin{tabular}{|c|c|c|c|}
\hline III & ND & $29.164 \pm 3.508$ \\
\hline IV & Vitexin (10.5), quercetin (17.0), luteolin (19.9), chrysoeriol (20.2) & $17.386 \pm 2.560$ \\
\hline V & Orientin (6.9), vitexin (10.5), quercetin (17.0), luteolin (18.5), & $17.611 \pm 3.980$ \\
chrysoeriol (20.2) & $6.721 \pm 9.403$ & $24.397 \pm 2.422$ \\
\hline VI & Vitexin (10.6), hyperoside/rutin (11.7), quercetin (17.0), luteolin & $19.816 \pm 4.913$ \\
\hline VII & Orientin (6.7), vitexin (10.6), hyperoside/rutin (11.8), quercetin & $38.923 \pm 0.432$ \\
\hline VIII & Aspalathin (6.6), quercetin (17.1), luteolin (18.3), chrysoeriol & $71.552 \pm 0.776$ \\
\hline IX & Vitexin (10.3), quercetin (17.7), luteolin (18.3), chrysoeriol (20.3) & $65.059 \pm 0.538$ \\
\hline EGCG & - & $61.582 \pm 0.879$ \\
\hline Kojic acid & - & $83.062 \pm 0.309$ \\
\hline
\end{tabular}

Figures in the bracket represent retention time measured in minute; ND: not detected

\section{Conclusion}

Over-accumulation of free radicals, specifically ROS is the primary cause of cellular oxidative stress and skin aging problems. These ROS are unstable molecules, they therefore interact with cellular components in order to become stable. These interactions may lead to cellular damage such as lipid peroxidation, protein fragmentation and skin aging. Effect of fermentation on green rooibos have been demonstrated and established from this study. Such effect resulted into enzymatic oxidation and chemical changes leading to changes in the composition of bioactive constituents thereby reading its biological activities. Further studies can further include in vivo investigation of the fractions and or compounds identified by HPLC on alleviating other factors of premature skin.

\section{Acknowledgements}

The Authors are grateful to Rooibos Limited, Clanwilliam, South Africa for donation of the plant material used for this study. Also, to Prof J.L. Marnewick of Oxidative Stress Research Centre and Prof Ahmed A. Hussein all from CPUT, South Africa for their financial support.

\section{Conflict of Interests}

The Author declare no conflict of interest.

\section{Reference}

1. Xing HY, Cai YQ Wang XF, Wang LL, Li P, et al.(2015) The cytoprotective effect of hyperoside against oxidative stress is mediated by the Nrf2ARE signaling pathway through GSK-3b inactivation. PLoS ONE 10(12): e0145183.

2. Ndlovu G, Fouche G, Tselanyane M, Cordier W, Steenkamp V (2013) In vitro determination of the anti-aging potential of four southern African medicinal plants. BMC Complementary and Alternative Medicine 13(304): 1-7

3. Birben E, Sahiner UM, Sackesen C, Erzurum S, Kalayci O (2012) Oxidative stress and antioxidant defense. World Allergy Organ Journal 5(1): 9-19.

4. Popoola OK, Marnewick JL, Rautenbach F, Ameer F, Iwuoha EI, et al. (2015) Inhibition of oxidative stress and skin aging-related enzymes by prenylated chalcones and other flavonoids from Helichrysum teretifolium. Molecules 20(4): 7143-7155.

5. Watson REB, Gibbs NK, Griffiths CEM, Sheraft MJ (2014) Damage to skin extracellular matrix induced by UV exposure. Antioxidant and Redox Signaling 21(7): 1063-1077.
6. Lötter D, Maitre D (2014) Modelling the distribution of Aspalathus linearis (Rooibos tea): Implications of climate change for livelihoods dependent on both cultivation and harvesting from the wild. Ecology and Evolution 4(8): 1209-1221.

7. Joubert E, Gelderblom WC, Louw A, De Beer D (2008) South African herbal teas: Aspalathus linearis, Cyclopia spp. and Athrixia phylicoides - a review. Journal of Ethnopharmacology 119(3): 376-412.

8. Huang M, Du Plessis J, Du Preez J, Hamman J, Viljoen A (2008) Transport of aspalathin, a Rooibos tea flavonoid, across the skin and intestinal epithelium. Phytotherapy Research 22(5):699-704.

9. Street RA, Prinsloo G (2013) Commercially important medicinal plants of South Africa: A review. Journal of Chemistry.

10. Joubert E, De Villiers OT (1997) Effect of fermentation and drying conditions on the quality of rooibos tea. IJFS International Journal of Food Science \& Technology 32(2): 127-134.

11. Marnewick JL, Gelderblom WCA, Joubert E (2000) An investigation on the antimutagenic properties of South African herbal teas. Mutation Research/Genetic Toxicology and Environmental Mutagenesis 471(1,2): 157-166.

12. Mckay DL, Blumberg JB (2007) A review of the bioactivity of South African herbal teas: rooibos (Aspalathus linearis) and honeybush (Cyclopia intermedia). Phytotherapy Research 21(1): 1-16.

13. Bramati L, Minoggio M, Gardana C, Simonetti P, Mauri P, Pietta P (2002) Quantitative characterization of flavonoid compounds in rooibos tea (Aspalathus linearis) by LCUV/DAD. Journal of Agriculture and Food Chemistry 50(20): 5513-5519.

14. Krafczyk N, Glomb MA (2008) Characterization of phenolic compounds in rooibos tea. Journal of Agriculture and Food Chemistry 56(9): 33683376.

15. Iswaldi I, Arráez-román D, Rodríguez-Medina I, Beltrán-Debón R, Joven J, Segura-Carretero A, Fernández-Gutiérrez A (2011) Identification of phenolic compounds in aqueous and ethanolic rooibos extracts (Aspalathus linearis) by HPLC-ESI-MS (TOF/IT). Analytical and Bioanalytical Chemistry 400(10): 3643-3654.

16. Ajuwon OR, Marnewick JL, Davids LM (2015) Rooibos (Aspalathus linearis) and its major flavonoids-potential against oxidative stressinduced conditions, InTechOpen. Basic Principles and Clinical Significane of Oxidative Stress DOI: 10.5772/61614.

17. Snijman PW (2007) Biological properties of selected flavonoids of rooibos (Aspalathus linearis). Master of Science in Chemistry University of the Western Cape South Africa.

18. Satyamitra M, Mantena S, Nair C, Chandna S, Dwarakanath B, Uma Devi P (2014) The Antioxidant Flavonoids, Orientin and Vicenin Enhance Repair of Radiation-Induced Damage. Scholarena Journal of Pharmacy and Pharmacology 1(1). 
19. Lin WL, Wang SM, Ho YJ, Kuo HC, Lee YJ, Tseng TH (2014) Ethyl acetate extract of Wedelia chinensis inhibits tert-butyl hydroperoxide-induced damage in PC12 cells and D-galactose-induced neuronal cell loss in mice. BMC Complementary and Alternative Medicine 14: 491.

20. Al-Dhabi NA, Arasu MV, Park CH, Park SU (2015) An up-to-date review of rutin and its biological and pharmacological activities. Excli Journal 14: 59-63.

21. Marnewick JL, Rautenbach F, Venter I, Neethling H, Blackhurst DM, Wolmarans P, Macharia M (2011) Effects of rooibos (Aspalathus linearis) on oxidative stress and biochemical parameters in adults at risk for cardiovascular disease. Journal of Ethnopharmacology 133(1): 46-52.

22. Wangthong S, Tonsiripakdee I, Monhaphol T, Nonthabenjawan R, Wanichwecharungruang SP (2007) Post TLC developing technique for tyrosinase inhibitor detection. BMC Biomedical Chromatography 21(1): 94-100.

23. Badarinath AV, Mallikarjuna RK, Madhu SC, Ramkanth S, Rajan, TVS, Gnanaprakash K (2010) A review on in-vitro antioxidant methods: Comparisions, correlations and considerations. International Journal of PharmTech Research 2(2): 1276-1285.

24. Cao G, Prior RL (1999) Measurement of oxygen radical absorbance capacity in biological samples. Methods in Enzymology 299: 50-62.

25. Snijman PW, Joubert E, Ferreira D, Li XC, Ding Y, Green IR, Gelderblom WC (2009) Antioxidant activity of the dihydrochalcones Aspalathin and Nothofagin and their corresponding flavones in relation to other Rooibos (Aspalathus linearis) Flavonoids, Epigallocatechin Gallate, and Trolox. Journal ofAgriculture and Food Chemistry 57(15): 6678-6684.

26. Chompo J, Upadhyay A, Fukuta M, Tawata S (2012) Effect of Alpinia zerumbet components on antioxidant and skin disease-related enzymes. BMC Complementary and Alternative Medicine 12: 106-114.

\section{ISSN: 2574-1241}

DOI: 10.26717/BJSTR.2019.20.003481

Olugbenga Kayode Popoola. Biomed J Sci \& Tech Res

This work is licensed under Creative Commons Attribution 4.0 License

Submission Link: https://biomedres.us/submit-manuscript.php
27. Cho JY, Yang X, Park KH, Park HJ, Park SY, Ham KS, Moon JH (2013) Isolation and identification of antioxidative compounds and their activities from Suaeda japonica. Food Science and Biotechnology, 22(6): 1547-1557.

28. Burton GJ, Jauniaux E (2011) Oxidative stress. Best Practice Research and Clinical Obstetry Gynaecology25(3): 287-299.

29. Carocho M, Ferreira I (2013) A review on antioxidants, prooxidants and related controversy: Natural and synthetic compounds, screening and analysis methodologies and future perspectives. Food and Chemical Toxicology 51: 15-25.

30. Nugroho A, Cha BC, Park HJ, Choi JK, Park JH, Lee KT (2009) Two new flavonol glycosides from Lamium amplexicaule $\mathrm{L}$. and their in vitro free radical scavenging and tyrosinase inhibitory activities. Planta Medica 75(4): 364-366.

31.Si Y-X, Yin S-J, Oh S, Wang Z-J, Ye S, Yan L, Yang J-M, Park Y-D, Lee J, Qian G-Y. (2012) An integrated study of tyrosinase inhibition by rutin: Progress using a computational simulation. Journal of Biomolecular Structure and Dynamics 29(5): 999-1012.

32. Joshi UJ, Gadge AS, D’mello P, Sinha R, Srivastava S, Govil G (2011) Antiinflammatory, antioxidant and anticancer activity of Quercetin and its analogues. I'nt Journal of Research in Pharma and Biomedical Science 2: 756-1766.

33. Hassan RA, Tawfik WA, Abou-Setta LM (2014) The flavonoid constituents of Leucaena leucocephala growing in Egypt, and their biological activity. African Journal of Traditional, Complementary, and Alternative Medicines, 11(1): 67-72.

34. Fang A, Wang S, Yuan D, Gong Y, Wang S (2016) Attenuation of oxidative stress of erythrocytes by plant-derived flavonoids, orientin and luteolin. Evidence-Based Complementary and Alternative Medicine.

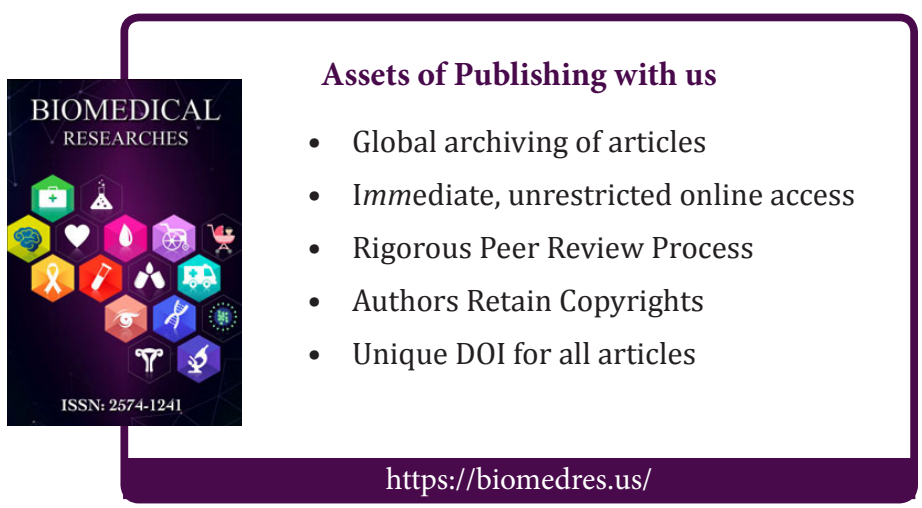

